\title{
Temporal Variation and Respons of Mangrove Soil on Solar Illumination Changes
}

\author{
Christophil Medellu ${ }^{1 *}$, Soemarno ${ }^{2}$, Marsoedi $^{2}$ and Sigfried Berhimpon ${ }^{3}$ \\ ${ }^{1}$ Department of Physic, Faculty of Science and Mathematics, State University of Manado, Jl. Tondano 95618, \\ North Sulawesi, Indonesia, e-mail: chrismedellu@yahoo.co.id, ${ }^{2}$ Graduate School of Natural Resource and \\ Environmental Management, Brawijaya University, Malang 65145, Indonesia. \\ ${ }^{3}$ Department of Coastal Resource Management, Faculty of Marine Science, Sam Ratulangi University, \\ Manado 95115, Indonesia. \\ "Corresponding author, phone: +62-431-321845; fax: +62-431-321866; e-mail: chrismedellu@yahoo.co.id
}

Received 12 December 2011 / accepted 16 April 2012

\begin{abstract}
Research on soil temperature in mangrove forest is a part of the mangrove ecosystem microclimate research. Studies on microclimate variables interaction, including soil temperature is important and interesting because it is associated with ecosystem and environmental changes, and the biota living in it. This study developed a mathematical modeling of soil temperatures and solar illumination in mangrove forest and the surrounding environment. Mathematical modeling function was constructed using data measured on three transects which different in ecosystem condition. The results showed that the mathematical modeling parameters produced the parameters of solar illumination and soil temperatures that were difference for the three transects. Time lag of soil temperature on solar illumination was also diference in the three transects due to the difference of penetration of sun radiation and soil inundation by sea water. These parameters also showed the differences between the soil temperature in mangrove with the soil temperature in terrestrial forest as studied by the former researcher. Our research demonstrated the charachteristic of soil temperature in mangrove, that was not merely controlled by sun radiation, but also it was contribute by the sea water and other factors.
\end{abstract}

Keywords: Mathematical modeling, soil temperature, solar illumination, time lag

\section{INTRODUCTION}

Tipically, soil below the mangrove canopy is diferent than the soil at the upper land. Geomorfologically, this soil is performed through the sedimentation process by river, ocean currents and waves. The unique of this soil characterized by the base layer is very gentle, loss of basic sediment, periodically flooding by tide etc. Brinkman et al. (2005) suggests that the roots of mangrove play the very important role to hold fine sediments, forming new land, and protect the ecosystem. According to Mazda and Ikeda (2006), and Sato (2003), particle size of material under the canopy of mangroves is varied but is more subtle than the size of the particles on the adjacent sea floor. Based on ecology, Krauss et al (2008) to quote Twiley (1998) to classify the mangrove forest into six types i.e. overwash islands, fringe, riverine, basin, hammock, and scrub forests. Futhermore Krauss et al. (2008) stated that these ecological types were different in soil type, salinity

J Trop Soils, Vol. 17, No. 2, 2012: 165-172

ISSN 0852-257X and hydroperiod. This classification was general and had been used in many studies on mangrove ecosystem. Kathiresan (2004) described this classification in context of three main factors that to control mangrove forest i.e. interior, rives dominated, and tide dominated.

Besides the physical processes, mangrove soil is controlled by organism activities likes crab and other animal that produce the hole in soil. Stieglitz et al. (2000) and Susilo (2004) stated that the density of crab holes increased the soil permeability and modified the properties of soil. Life of biota and its role in soil formation under mangrove forest is strongly influenced by the microclimate such as radiation intensity, air temperature and humidity, soil temperature and moisture, and salinity (Snedaker 1989). Microclimate including soil temperature is the important part of studies on mangrove ecosystem. Mangrove forest grows in the specific microclimate range. According to Kathiresan (2004), mangrove forest grows at water temperature of $24^{\circ} \mathrm{C}$ in average, and air temperature more than $20^{\circ} \mathrm{C}$ with its fluctuation smaller than $5^{\circ} \mathrm{C}$. 
Microclimate studies on mangrove ecosystem are very limited. We do not yet have enough microclimate data (including soil temperature) of mangrove ecosystems. Microclimate parameters that have been used in terrestrial forest research can be used to characterize the microclimate of mangrove ecosystem. Separated solution of thermal diffusion as the basic concept of microclimate changes in ecosystem, allows for developing the mathematical modeling and analysis of spatial variation and temporal changes of microclimate variables separately. This research developed the mathematical modeling of soil temperature under the mangrove canopy, and its respons to the solar radiation. The study was conducted on three transect which different in ecosystem condition i.e. the structure of the basin, the adjacent environment, the fragmentation, and canopy cover density. Parameters such as maximum soil temperature difference inside and outside the mangrove forest, lag of soil temperatures to the illumination changes were analyzed comparatively between transects. The parameters under study can show the difference between transects and between positions along the transects, related to the differences in ecosystem conditions. The procedures which will be developed in this research and the resulting data can be a reference for advanced research on mangrove ecosystem, including the biota living in it.

\section{MATERIALS AND METHODS}

\section{Study Site}

The research was conducted at the Village of East Ratatotok. The area of mangrove forests was about 2,400 $\mathrm{m}^{2}$. Here, we choosed three transect which different in forest structure and the adjacent environment. The first transect was adjacent to a paved road, the front overgrown by Rhizophora with the canopy density of $86 \%-95 \%$. At a distance of $14 \mathrm{~m}$ to the inside, there were fragments with mangrove plants of various types, canopy density of $65 \%-72 \%$. Classification of topography was forest basin. The second transect faced to the sea, topographically classified as fringe forest, and was overgrown by Rhizophora with canopy density $85 \%-92 \%$. The third transect was adjacent to the beach which was overgrown by high trees of coastal vegetation. Classification of topography was basin forest. The density of mangrove canopy cover was $65 \%-72 \%$.

At each transect, measurements were done at nine positions, namely position-1 and-2, respectively at $4 \mathrm{~m}$ and $2 \mathrm{~m}$ outside the edge of the mangrove, position- 3 as the reference position $(\mathrm{x}=$ 0 ) at the edge of the mangrove; position- 4 to 9 were $1 \mathrm{~m}, 2 \mathrm{~m}, 4 \mathrm{~m}, 8 \mathrm{~m}, 16 \mathrm{~m}$, and $32 \mathrm{~m}$ into the mangrove forest. The logarithmic distance for measurement positions was used based on the assumption of spatial variation pattern in form of exponential function. The gradient was steepest around the edge, and more data were needed to construct the mathematical function of research variables (Davies-Colley et al. 2000).

\section{Variable Measurement}

Due to limitation in equipments the research variables were measured by moving from position to position (moving station system). Solar illumination was measured using a four-in-one digital instrument, which simultaneously measured four variables i.e. the solar illumnitaion, air temperature, air humidity and wind velocity. The measuring capacity of equipmet was 0.1 lux.

For each position, 13 illumination data were obtained during the measurement started at 06.00 a.m. until 18.00 p.m., with 1 hour interval of measurement.

Soil temperatures were measured using High Barbecue Thermometer A-204L, with a measuring capacities of $0.1^{\circ} \mathrm{C}$ in range $-50^{\circ} \mathrm{C}$ to $300^{\circ} \mathrm{C}$. The recorded soil temperature data was the soil surface temperatures which were measured at the depths of less than $0.5 \mathrm{~cm}$. For each position 25 data were obtained, as the results of measurements started at 19.00 p.m. on May 26, 2011 until 19.00 p.m. on May 27, 2011. Interval of measurement at each position was 1 hour.

\section{Modelling Analysis}

Steps of modeling and analysis, starting with the modeling of diurnal dynamics of soil temperature and solar illumination. Modeling was performed on each measurement position. Theoretically, the diurnal changes soil temperature to follow the sinusoidal pattern of the solar radiation changes. The mathematical modeling of soil temperature as well as solar illumination were using periodic function i.e. Fourier series. Modeling the Fourier function of field data are using the formula:

$$
\begin{aligned}
& \mathrm{T}(\mathrm{t})=\sum^{\mathrm{N} / 2}=\mathrm{a}_{\mathrm{m}} \cos \omega_{\mathrm{m}} \mathrm{t}+\mathrm{b}_{\mathrm{m}} \sin \omega_{\mathrm{m}} \mathrm{t} \\
& \omega_{\mathrm{m}}=2 ð \mathrm{~m} / \mathrm{N} \\
& \mathrm{a}_{\mathrm{m}}=2 / \mathrm{N} \sum^{\mathrm{N}-1}=\mathrm{f}(\mathrm{t}) \cos \omega_{\mathrm{m}} \mathrm{t} \\
& \mathrm{b}_{\mathrm{m}}=2 / \mathrm{N} \sum^{\mathrm{t} \overline{\mathrm{N}}^{0}-1}=\mathrm{f}(\mathrm{t}) \sin \omega_{\mathrm{m}} \mathrm{t}
\end{aligned}
$$

$\mathrm{m}=$ the number of harmonic, $\mathrm{N}=$ the number of data, $\mathrm{t}=$ the independent variable: time and $\mathrm{T}_{\text {soil }}$ 
represents the dependent variable i.e. soil temperature or solar illuminaton.

Illumination (I) and soil temperature $\left(\mathrm{T}_{\text {soil }}\right)$ data were bias, arose by not simultaneously of measurements (moving station system), corrected through the steps of data synchronization. Data synchronization was obtained by shifting the independent variable $(\mathrm{t})$ according to time difference in measuring data between positions. Submitted to the Fourier function for I and $\mathrm{T}_{\text {soil }}$ we found the synchronous data of $\mathrm{I}$ and $\mathrm{T}_{\text {soil }}$. Using the Fourier function of $\mathrm{I}$ and $\mathrm{T}_{\text {soil }}$, we generate the modeling data by taking the interval of dependent variable Ät $=0.1$ hours. This stage produced 120 synchronous data of solar illumination (I) and 250 synchronous data of soil temperature $\left(\mathrm{T}_{\text {soil }}\right)$. Data used for the determination of time lag between $\mathrm{I}$ and $\mathrm{T}_{\text {soil }}$ was the data results of modeling for the interval of 6.00 a.m. to 6.00 p.m. . The number of pairs of data $\left(\mathrm{I}, \mathrm{T}_{\text {soil }}\right)$ was 120 . The time lag $\mathrm{I}-\mathrm{T}_{\text {soil }}$ was obtained by shifting of one variable function to another variable function.

In this study the function of illumination is shifted backward, relative to the soil temperature function. Cross correlation formula for determination of time lag is:

$\left.r=\sum\{(x(i)-m x)) .(y(\mathrm{i}-d)-m y)\right\} / \operatorname{sqr}\left\{\sum\left(x((i)-m x)^{2}\right\}\right.$. $\operatorname{sqr}\left\{\sum\left(y((i-d)-m y)^{2}\right\}\right.$

Here, $r=$ the correlation coefficient, $n=$ number of data, $\mathrm{m}=\mathrm{a}$ constant, $\mathrm{I}=\mathrm{a}$ count of the data, and $\mathrm{d}=$ the length of time shifting of variable y (i.e. I) to variable $\mathrm{x}$ (i.e. $\mathrm{T}_{\text {soil }}$ ). Time-lag between $\mathrm{x}$ and $\mathrm{y}$ is obtained if $r$ is maximum. Here the shifting of variables can be exchanged between $\mathrm{x}$ and $\mathrm{y}$.

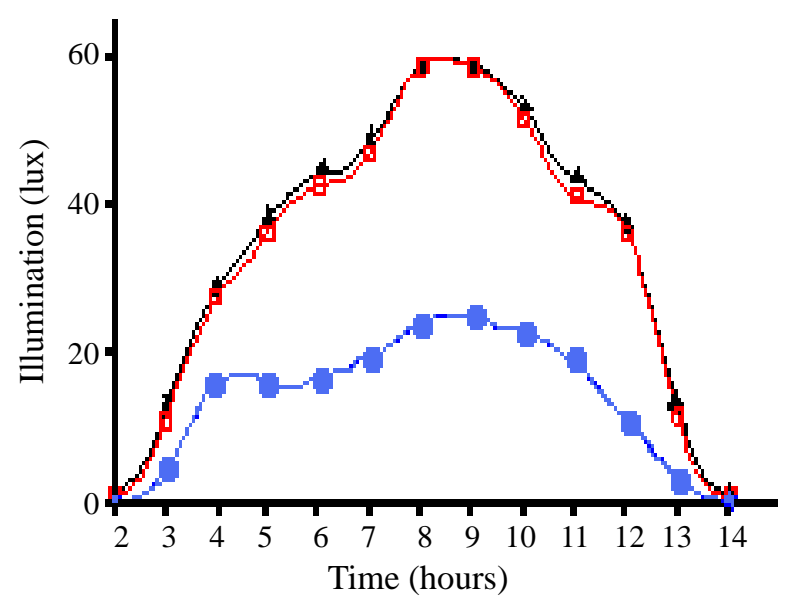

Figure 1. Temporal changes of solar illumination at transect-1, position-1 ( $\downarrow=4 \mathrm{~m}$ from the edge), position-3 ( $-=$ at the edge ), and position $-9(-=32 \mathrm{~m}$ into the forest $)$.

\section{RESULTS AND DISCUSSION}

\section{Diurnal Dynamics of Solar Illumination and Soil Temperature}

The example of mathematical modelling of solar illumination and soil temperature are presented in Figure 1 and 2. The graph represents the measurement data (dot, rectangle, and triangle symbols) and modeling function (line) for three positions.

The example of solar illumination function for position-3, transect-1 (Figure-1) are as follows:

$$
\begin{aligned}
I(t)= & 32.746-25.119 \cos (2 ð t) / 12-10.294 \sin (2 ð t) / 12- \\
& 5.454 \cos (4 ð t) / 12-0.652 \sin (4 ð t) / 12-1.811 \cos (6 ð t) / \\
& 12-2.671 \sin (6 ð t) / 12-0.919 \cos (8 ð t) / 12+1.721 \\
& \sin (8 ð t) / 12+0.454 \cos (10 ð t) / 12+1.100 \sin (10 ð t) / \\
& 12+1.003 \cos (ð t)+1.390 \sin (ð t) \ldots \ldots \ldots \ldots \ldots \ldots \ldots . . .[3]
\end{aligned}
$$

Using the equation (3) as a continous function, we can get I, by submission any values t. For smaller time interval $(\Delta \mathrm{t})$, we get more I data in range of 13 hours (06.00 a.m. - 18.00 p.m.). Using the equation (3) we could synchronize I functions between position that perform using the data which were measured not simultaneously (moving station system). Synchronization between positions was important in this research, for determination of spatial variability of illumination, illumination gradient at the edge, the depth of edge effect, and the time lag between illumination and soil temperature. The example of soil temperature function for position-3, transect-1 (Figure-2) are as follows:

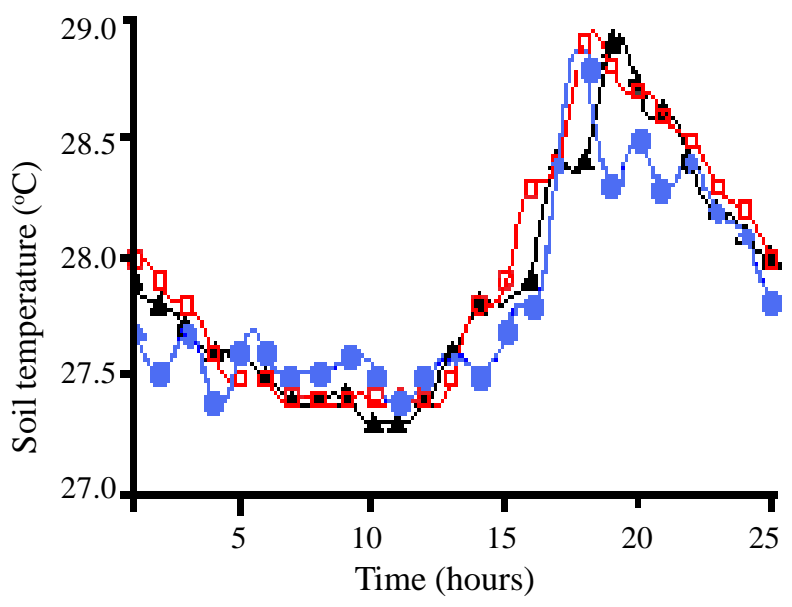

Figure 2. Temporal changes of soil temperature at transect-1, position-1 ( $\downarrow=4 \mathrm{~m}$ from the edge), position-3 ( $\square=$ at the edge ), and position- $9(-=32 \mathrm{~m}$ into the forest). 
$\mathrm{T}(\mathrm{t})=27.944+0.272 \cos (2 ð \mathrm{t}) / 24-0.602 \sin (2 ð \mathrm{t}) / 24-$ $0.176 \cos ($ ð $) / 24+0.006 \sin (4 ð \mathrm{t}) / 24+0.032$ $\cos (6 ð \mathrm{t}) / 24+0.079 \sin (6 ð \mathrm{t}) / 24+0.003 \cos (8 ð \mathrm{t}) /$ $24+0.001 \sin (8 ð \mathrm{t}) / 24-0.018 \cos (10 ð \mathrm{t}) / 24-0.014$ $\sin (10 ð \mathrm{t}) / 24-0.036 \cos (12 ð \mathrm{t}) / 24+0.018 \sin (12 ð \mathrm{t}) /$ $24+0.012 \cos (14 ð \mathrm{t}) / 24+0.002 \sin (14 ð \mathrm{t}) / 24+$ $0.009 \cos (16 ð \mathrm{t}) / 24-0.016 \sin (16 ð \mathrm{t}) / 24-0.005$ $\cos (18 ð \mathrm{t}) / 24-0.012 \sin (18 ð \mathrm{t}) / 24-0.026 \cos (20 ð \mathrm{t}) /$ $24+0.023 \sin (20 ð \mathrm{t}) / 24+0.018 \cos (22 ð \mathrm{t}) / 24-$ $0.029 \cos (ð \mathrm{t})-0.037 \sin (ð \mathrm{t})$.

As equation (3), the continous function (equation 4) allows us to generate more data by taking smaller time interval $(\Delta \mathrm{t})$. Using this equation we could synchronize modeling data between positions, and then we determined the spatial variability function for soil temperature, its gradient and edge effect penetration into the mangrove forest. Our soil temperature function was different in time range with the illumination function. The time range of soil temperature was between 19.00 p.m. to 19.00 p.m. of the next day.

The illumination data presented in Figure 1 was the measured data divided by 1,000 . The maximum solar illumination at the edges of mangroves for transect-1, 2, and 3, were 59,000 lux, 59,500 lux and 51,210 lux, respectively. These maximum values were reached at $12.00 \mathrm{a} . \mathrm{m}$. The weather was bright during the measurement. The maximum differences of solar illumination between the edge and position of 32 meters from the edge of transect 1, 2, and 3 were respectively : 34, 800 lux, 34,300 lux, and 25, 400 lux. These maximum diferences were occured at 12.00 a.m.

The pattern of diurnal changes graphics showed the influence of mangrove canopy to reduce the solar illumination at the depth position inside the mangrove (position $32 \mathrm{~m}$ from the edge). The decreasing of solar illumination was diferent between transects due to the difference in canopy density. For each transect, solar illumination decreased by the increasing of distance from the edge into the forest. These phenomena were the same as in terrestrial forest (De Siquerian et al., 2004; Davies Colley et al. 2000; Chen et al. 1995; Hennenberg et al. 2008; Pinto et al. 2010)

Figure- 2 shows the pattern of temporal changes of soil temperature which were more complex than the illumination. Temporal function of soil temperature graphs at position 1, 3, and 9 showed small fluctuations during the night (19.00 p.m. to 05.00 a.m., or abscissa scale of 0 to 11) than the day (at 06.00 a.m. to 18:00 p.m., or abscissa scale of 12 to 24). The results of this study were inline with the results of the study by Chen et al. (1999), which stated that at the day, variations in soil temperature were higher than at night. Between the hours of $23.00 \mathrm{p} . \mathrm{m}$. to $05.00 \mathrm{a} . \mathrm{m}$., the soil temperature in mangrove forests was higher than the temperature at the edge and outside the forest. Throughout the day, the soil temperature in the mangrove forest was lower than the temperature at the edge and outside the forest. The three transects showed the same pattern of temporal changes of soil temperature. The highest soil temperature at the edge of the forest for the transect 1,2 , and 3 respectively were: $28.9^{\circ} \mathrm{C}, 29.1{ }^{\circ} \mathrm{C}$ and $29^{\circ} \mathrm{C}$. The highest soil temperature was occurred at 12.00 . These results are consistent with the results of Chen et al. (1999), which stated that the maximum temperature was attained at noon or after noon, depending on geographic location, landscape position and canopy structure. In transect-1 and 3, the highest soil temperature occurred when the surface soil was not inundated by sea water. At transect-2, the pick of soil temperature occurred when sea water inundate the soil surface as $12 \mathrm{~cm}$ depth. The highest soil temperature at transect- 1 and 3 were caused by the maximum direct penetration of solar radiation. At 12.00 a.m. the sun radiation penetration through the low density canopy at transect 1 and 3 were maximum. At transect 2, the warm sea water inundated the soil and delivered the thermal energy to soil surface.

Daytime soil temperature difference between the edge and the interior ( 32 meters from the edge) for the three transects was around $0.5^{\circ} \mathrm{C}$. This result was lower than Spittlehouse (2004), that found the difference of soil temperature for terrestrial forest was around $10-15^{\circ} \mathrm{C}$. At night the soil temperature inside the mangrove for the transect-1, 2, and 3 respectively were $0.2^{\circ} \mathrm{C}, 0.4^{\circ} \mathrm{C}$ and $0.3^{\circ} \mathrm{C}$ higher than at the edge and outside. The results of this study were lower than the results founded by (Chen et al. 1995; Brosofske et al. 1997; Stathers et al. 2001, quoted by Spittlehouse (2004) i.e. around $1-2^{\circ} \mathrm{C}$.

The difference in soil temperature between the mangrove and the terrestrial forest, showed the thermal characteristics of mangrove ecosystem that was different to forest in the mainland. These differences were caused by the inundation and water mass movement that had a certain temperature. Sea water temperature due to receiving the heat energy from the sun during the day, can affect the soil temperature inside the mangrove forest (Mazda and Wolanski 2009). At the daytime, the high temperature water will raise the soil temperature under the closed canopy so the difference with the outside will be lower. At night, the sea water which low temperature, flow into the mangrove to decrease soil temperature inside the mangrove. Furthermore, 
the soil temperature differences between inside and the edge or outside the mangrove was lower than in terrestrial forest. The phenomenon of soil temperature changes due to sea water inundation did not occur in the forests in the mainland. The soil temperature was changed due to inundation, spatially relatively complex because it was determined by topographic conditions, substrate material, the supply of fresh water from land etc. This was a characteristic of soil temperature of mangrove.

\section{Cross Correlation and the Time-Lag between Solar Illumination and Soil Temperature}

The procedure for determination of time-lag that described in research methods, produced the dynamic function of solar illumination and soil temperature as presented at Figure 3, 4, and 5. The black color graph represented the illumination dynamic before shifting $\left(\mathrm{I}_{\mathrm{b}}\right)$ while the red color graph represented the illumination after shifting $\left(I_{a}\right)$, for time range of 06.00 to 18.00 . Here we adjusted the range of time of soil temperature to the time range of illumination. The blue color graph represented the dynamic of soil temperature $\left(\mathrm{T}_{\text {soil }}\right)$ in the same range of time ( $\mathrm{t}$ ). Cross-correlation coeficients between $I_{b}$ and $T_{\text {soil }}$ are presented in column-2 of Table 1,2, and 3. Cross-correlation coefficients between $I_{a}$ and $T_{\text {soil }}$, are presented in column-3 of Table-1, 2, and 3. The length of shifting $\left(I_{b}\right.$ to $\left.I_{a}\right)$ that yielded the maximum coefficient of

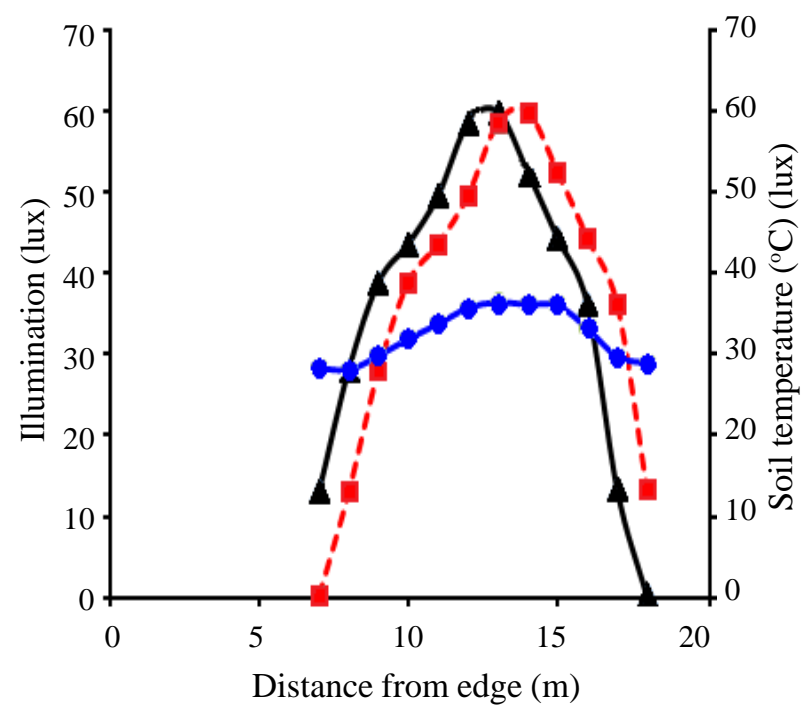

Figure 3. Graphics of illumination and soil temperature of transect-1, position-1 (4 m outside the edge). $\longrightarrow \mathbf{=}=$ illmunation before shifting, $=-1-==$ illmunation after shifting, and $\longrightarrow=$ soil temperature.
Table 1. Cross-correlation and the lag between solar illumination and soil temperature, at transect-1.

\begin{tabular}{cccc}
\hline Position & $\begin{array}{c}\text { Cross correlation } \\
\text { before shifting }\end{array}$ & $\begin{array}{c}\text { Coefficient } \\
\text { after shifting }\end{array}$ & $\begin{array}{l}\text { Time lag } \\
\text { (hour) }\end{array}$ \\
\hline 1 & 0.401 & 0.942 & 1.8 \\
2 & 0.314 & 0.910 & 1.9 \\
3 & 0.343 & 0.963 & 2.0 \\
4 & 0.181 & 0.935 & 2.3 \\
5 & 0.178 & 0.909 & 2.3 \\
6 & 0.221 & 0.913 & 2.3 \\
7 & 0.168 & 0.884 & 2.4 \\
8 & 0.146 & 0.875 & 2.4 \\
9 & 0.281 & 0.898 & 2.4 \\
\hline
\end{tabular}

Table 2. Cross-correlation and the lag between solar illumination and soil temperature, at transect-2.

\begin{tabular}{cccc}
\hline Position & $\begin{array}{c}\text { Cross correlation } \\
\text { before shifting }\end{array}$ & $\begin{array}{c}\text { Coefficient } \\
\text { after shifting }\end{array}$ & $\begin{array}{c}\text { Time lag } \\
\text { (hour) }\end{array}$ \\
\hline 1 & 0.698 & 0.941 & 1.4 \\
2 & 0.670 & 0.942 & 1.5 \\
3 & 0.718 & 0.976 & 1.3 \\
4 & 0.574 & 0.913 & 1.6 \\
5 & 0.613 & 0.910 & 1.5 \\
6 & 0.719 & 0.847 & 1.5 \\
7 & 0.517 & 0.893 & 1.7 \\
8 & 0.534 & 0.883 & 1.7 \\
9 & 0.537 & 0.865 & 1.6 \\
\hline
\end{tabular}

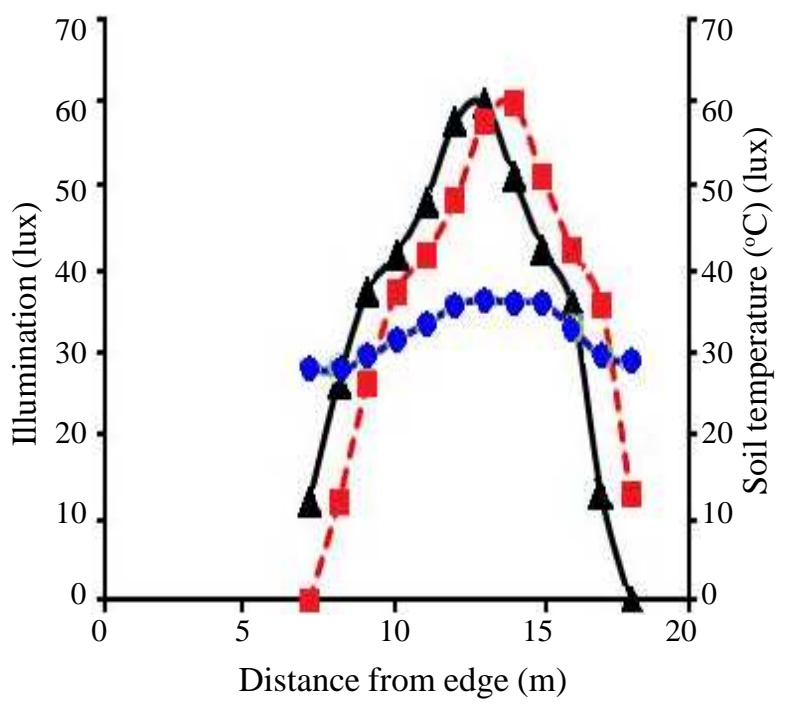

Figure 4. Graphics of illumination and soil temperature of transect-1, position-3 (edge of mangrove). $\longrightarrow \mathbf{=}=$ illmunation before shifting, $=-1==$ illmunation after shifting, and $\longrightarrow=$ soil temperature. 
Table 3. Cross-correlation and the lag between solar illumination and soil temperature, at transect-3.

\begin{tabular}{cccc}
\hline Position & $\begin{array}{c}\text { Cross correlation } \\
\text { before shifting }\end{array}$ & $\begin{array}{l}\text { Coefficient } \\
\text { after shifting }\end{array}$ & $\begin{array}{l}\text { Time lag } \\
\text { (hour) }\end{array}$ \\
\hline 1 & 0.612 & 0.859 & 1.5 \\
2 & 0.632 & 0.879 & 1.4 \\
3 & 0.686 & 0.924 & 1.5 \\
4 & 0.629 & 0.855 & 1.8 \\
5 & 0.711 & 0.770 & 1.6 \\
6 & 0.735 & 0.851 & 1.6 \\
7 & 0.653 & 0.836 & 1.5 \\
8 & 0.655 & 0.849 & 1.6 \\
9 & 0.602 & 0.829 & 1.6 \\
\hline
\end{tabular}

cross correlation, are presented in column-4 Table1,2 , and 3 .

Maximum cross correlation coefficient for each position at transects 1,2, and 3 was high enough. Except for the position-5 transect-3, cross correlation coefficient was $r<0.83$. Correlation of $\mathrm{I}_{\mathrm{a}}-\mathrm{T}_{\text {soil }}$ on the basis of time $t$, indicated that the pattern of soil temperature under the mangrove canopy was changed followed the pattern of solar illumination. It can also be seen through the graph in Figure 3, 4, and 5.

Outcomes of modeling and analysis of time lag were different between positions and transects. Transect-1 showed gradually increasing of time lag according to the distance from the edge. Transect 2 and 3 showed a more complex spatial variation (up or down along the transects). At the edge and outside the mangrove forest, the time lag of $\mathrm{I}_{\mathrm{a}}-\mathrm{T}_{\text {soil }}$ in transect-1 was higher than in transect- 2 and 3. Inside the mangrove, time lag in transect- 1 was also higher than in transect-2 and 3. At a distance of $8 \mathrm{~m}$ to $32 \mathrm{~m}$ transect-1, the time lag increased 2.3 hours to 2.4 hours. For the same depth in transects 2 and 3 , the time lag was fluctuated between 1.5 hours to 1.8 hours.

Spatial changes of time lag $\mathrm{I}_{\mathrm{a}}-\mathrm{T}_{\text {soil }}$ were slightly different than the time lag between solar illumination and the air temperature $\left(\mathrm{I}_{\mathrm{a}}-\mathrm{T}_{\text {air }}\right)$, at the same transect. Spatial variation of time lag $\mathrm{I}_{\mathrm{a}}-\mathrm{T}_{\text {air }}$ from the edge to the centre of mangrove forests varied between 1.1 hours to 1.3 hours (Medellu et al. 2011). Time lag $\mathrm{T}_{\text {air }}-\mathrm{T}_{\text {soil }}$ in transects 2 and 3 varied between 0.4 to 0.6 hours. Time lag of $\mathrm{T}_{\text {air }}{ }^{-}$ $\mathrm{T}_{\text {soil }}$ in transect- 1 varied between 0.7 to 0.8 hours. These results were lower than found by DaviesColley et al. (2000), i.e. around one to two hours. According to Davies-Colley et al. (2000), the delay of soil temperature to air temperature changes was caused by conduction of thermal energy from the surface into a depth of soil temperature measurements $(100 \mathrm{~mm})$. Our results were also lower than Spittlehouse et al. (2004) which recorded the lag of soil temperature to the air temperature in terrestrial forest about three hours. Zheng et al. (2000), argued that the time lag I $-\mathrm{T}_{\text {soil }}$ decreased two to three hours, due to deforestation. These results were inline with the results on the transect1 and 3 where the time lag to be low at the position where the canopy density was low. In these positions, the higher penetration of solar radiation caused the rapid increasing of soil temperature to follow the irradiation changes during day. At night, when the outside air temperature drops, the thermal diffusion occurs from the inside to the environment through the canopy gap. This yield the inside air and soil temperature becomes closed to the outside air and soil temperature.

Significant difference of time lag $\mathrm{I}-\mathrm{T}_{\text {soil }}$ in mangrove and the mainland forest, was physically due to differences in energy received by the ground surface. Spatial variations of time lag $\mathrm{I}-\mathrm{T}_{\text {soil }}$ was more complex than the spatial variation of time lag $\mathrm{I}-\mathrm{T}_{\text {air }}$. The soil temperature changes under the mangrove canopy, was not influence by solar illumination only. Other factors that potentially influence the soil temperature changes in the mangrove forest is the inundation of soil surface by sea water. Sea water temperature can be increasing or decreasing the soil temperature. Furthermore, spatial variability of soil temperature suspected depends on topography, substrat material, fresh water flow etc. Topographically, the floor form determine the area and duration of inundation. It was shown by the time lag fluctuation in transect-2 (fringe forest) which smaller than in transect-1 (basin forest). The soil surface in transect-2, inundated by sea water nearly during the time of measurement, while the inundation in transect -1 , was only about 2.5 to 3 hours. The differences of material conductivity determine the solar energy absorbed and stored at the upper layer of the soil. The fine surface material under the Rhizophora suspected have the different thermal conductivity with a more coarse material under Sonneratia. Study on thermal conductivity of soil surface material do not include in our research, but this section is important to study more deeply as a part of physical characterization of soil in mangrove forest. However, this research showed the diurnal changes of soil temperature to follow the sun radiation. We have proved that the soil temperature was a specific physical properties of the area being studied. Our 
procedure and data are important for monitoring the mangrove structure changes, and as a references for study of biological relationships with physical factors in mangrove forest

\section{CONCLUSIONS}

Mathematical modeling of temporal changes of soil temperature and its response to solar radiation, produced parameters that can indicate the characteristics of the studied transect. Maximum soil temperature, maximum difference of soil temperature at the edge and interior, time lag and its spatial variation were different for the three transects. Soil temperature changes were not merely caused by the direct sun radiation, but also controlled by sea water inundation, fresh water flow, surface material, etc. This study needs to be developed, among others about the thermal conductivity of soil materials, and energy supply process in soil. Study on the physical properties of soil is important as a references for research of mangrove growth and biota living in it.

\section{ACKNOWLEDGEMENTS}

Acknowledgements are submitted to the Government of Southeast Minahasa District on permission and support in the implementation of research. Thanks are also conveyed to the police sector Ratatotok which ensures the security during the measurement or data collection.

\section{REFERENCES}

Brosofske KD, J Chen, RJ Naiman and JF Franklin. 1997. Harvesting effects on microclimate gradient from small streams uplands in Western Washington. Ecol Appl 7 (4): 1188-1200.

Brinkman R, G Wattayakorn, E Wolanski, S Spagnol and K Marshall. 2005. Storm-driven erosion of fine sediment and its subsequent transport and trapping in fringing mangroves, Sawi Bay, Thailand. J Coast Res 42: 211-220.

Chen J, JF Franklin and TA Spies. 1995. Growing-season microclimatic gradients from clearcut edges into oldgrowth Douglas-Fir Forests. Ecol Appl 2 (1): 74-86.

Chen J and JF Franklin. 1997. Growing season microclimate variability within an old-growth Douglas-fir forest. Climate Res 8: 21-34.

Chen J, SC Saunders, TR Crow, RJ Naiman, KD Brosofske, BL Brookshire, and JF Franklin. 1999. Microclimate forest ecosystem and landscape ecology. BioScience 49 (4): 38-48.

Davies-Colley RJ, GW Payne and M van Elswijk. 2000. Microclimate gradients across a forest edge. New Zealand J Ecol 24 (2): 111-121.
De Siquerian LP, MB de Matos, DMS Matos, R de Cassia, Q Portela, MIG. Braz and L Silvalima. 2004. Using the variances of microclimate variables to determine the edge effects in Small Atlantic rainforest fragment, South Eastern Brazil. Ecotropica 10: 5964.

Hennenberg KJ, D Goetze, J Szarzynski, B Orthmann, B Reineking, I Steinke and S Porembski. 2008. Detection of seasonal variability in microclimatic borders and ecotones between forest and savanna. Basic Appl Ecol 9 (3): 275-285.

Kathiresan K. 2004. Ecology and Environment of Mangrove Ecosystems. Centre of Advanced Study in Marine Biology, Annamalai University, pp. 101115 .

Krauss KW, CE Lovelock, KL McKee, L Lo'pezHoffman, SML Ewe and WP Sousa. 2008. Environmental drivers in mangrove establishment and early development: A review. Aquatic Botany 89: 105-127.

Mazda Y and Y Ikeda. 2006. Behavior of the groundwater in a riverine-type mangrove forest. Wetlands Ecol Manage 14: 477-488.

Mazda Y and E Wolanski. 2009. Hydrodynamics and modeling of water flow in mangrove areas. Coastal Wetlands: An Integrated Ecosystem Approach. Elsevier, pp. 245-264.

Medellu C, Soemarno, Marsoedi and S Berhimpon. 2011. Time-lag between Sun Radiation and Air Temperature as Parameter for Characterization of Mangrove Ecosystems. Paper presented in International Seminar on Sustainable Natural Resources and Environment Management, Manado 18 November 2011.

Pinto SRR, G Mendes, AMM Santos, M Dantas, M Tabarelli and FPL Melo. 2010. Landscape attributes drive complex spatial microclimate configuration of Brazilian Atlantic forest fragments. Trop Conserv Sci 3 (4): 389-402.

Sato K. 2003. Reality of sedimentation in mangrove forest by the tide and dischargeInvestigation on trapped amount of deposit in a serial of high tides. A summary on the Mangrove Study in Okinawa (FY2000-2002), Research Institute for Subtropics, pp. 58-59.

Saunders SC, J Chen, TR Crow and KD Brosofske. 1998. Hierarchical relationship between landscape structure and temperature in managed forest landscape. Landscape Ecol 13: 381-395.

Snedaker SC. 1989. Overview of ecology of mangroves and information needs for Florida Bay. Bull Marine Sci 44: 341-347.

Spittlehouse DL, RS Adams and RD Winkler. 2004. Forest, Edge, and Opening Microclimate at Sicamous Creek. Research Report of Forest Science Program, Ministry of Forest, British Coulombia.

Stieglitz T, PV Ridd and P Muller. 2000. Passive irrigation and functional morphology of crustacean burrows ina tropical mangrove swamps. Hydrobiologia 421: 69-76. 
Susilo A. 2004. Groundwater flow in arid tropical tidal wetlands and estuaries [Ph.D. Thesis] in the School of Mathematical and Physical Sciences, James Cook University.
Zheng D, J Chen, B Song, M Xu, P Sneed and R Jensen. 2000. Effects of silvicultural treatments on summer forest microclimate in southeastern Missouri Ozarks. Climate Res 15: 45-59. 